\title{
Histological and Immunohistochemical Study of the Effects of Tramadol Administration on the Ovaries of Adult Albino Rats and the Possible Recovery After its Withdrawal
}

\section{Original Article}

Hala Zein Elabdin Mohamed and Heba Kamal Mohamed

Department of Human Anatomy and Embryology, Faculty of Medicine, Assiut University, Assiut, Egypt

\begin{abstract}
Background: Tramadol hydrochloride is a centrally active synthetic opioid. Tramadol is known to be highly effective in the treatment of the pain.

Aim of the Work: The present work was conducted to outline the deleterious effects of tramadol administration on the ovaries of adult albino rats and the possible recovery after the tramadol withdrawal.

Materials and Methods: Thirty adult virgin female albino rats were used in this study. They were classified into two groups; control group and experimental group. The experimental group is further divided into treated and withdrawal. Both the treated and the withdrawal groups were subcutaneously injected with Amadole in a dose of $40 \mathrm{mg} / \mathrm{kg}$ body weight three consecutive times weekly for 8 weeks while the withdrawal group was kept for another 8 weeks without treatment for the detection of the possible recovery. The rats were sacrificed. The ovaries were processed for histological and immunohistochemically study. Morphometric study was done in addition.

Results: In the treated group, the ovaries had degenerated ovarian follicles with loss of their normal architecture and some atretic follicles could be detected. The secondary follicles showed primary oocytes surrounded by granulosa cells. The surrounding granulosa cells appeared swollen, disrupted, irregular with degenerated vacuolated cytoplasm. The cortical blood vessels were dilated and congested. The withdrawal group revealed degenerative changes that were comparable to the treated group.
\end{abstract}

Conclusion: Tramadol induced deleterious effects on The structure of the ovary .These impairment were not improved with the withdrawal of tramadol.

Received: 21 February 2020, Accepted: 05 April 2020

Key Words: Histological study, immunohistochemistry study female adult virgin rat, ovary, tramadol.

Corresponding Author: Hala Zein Elabdin Mohamed, PhD, Department of Human Anatomy and Embryology, Faculty of Medicine, Assiut University, Assiut, Egypt, Tel.: +2 088 2345324, E-mail: hala.zeinelabdin@aun.edu.eg

ISSN: 1110-0559, Vol. 44, No.1

\section{INTRODUCTION}

Pain is considered as a major health problem and opioid drugs are still the first choice for the relief of moderate and severe pain ${ }^{[1]}$. Tramadol hydrochloride is a centrally active synthetic opioid that is proved to be highly effective in pain treatment ${ }^{[2]}$. Its efficiency as analgesic ranges between weak opioid and morphine action ${ }^{[3]}$. Tramadol has two acceptable mode of action; one of them is binding to $\mu$-opioid receptors and the other is serotonin and noradrenaline reuptake inhibition ${ }^{[4]}$. Tramadol addiction has been increasingly reported in young adults ${ }^{[5]}$ and addicts substituted tramadol use for herion ${ }^{[6]}$.

Long term use of opioids causes structural alterations of neurons ${ }^{[7]}$. Furthermore the endocrinopathy induced by opioid should be considered especially in the patient receiving daily opioid treatment ${ }^{[8]}$. A high index of suspicion for the occurrence of hypogonadism in the patients who are treated with opioid for a period longer than a few weeks ${ }^{[9]}$. The tramadol absorption takes place in the upper part of the small intestine, its metabolism occurs in the liver and its by-products are excreted through the kidneys. So the repeated administration of tramadol results in the accumulation of its toxic metabolites ${ }^{[10]}$.

So the aim of the present study was to determine the deleterious effects of tramadol treatment as well as the possibility of recovery after its withdrawal on the ovary of adult female virgin albino rats.

\section{MATERIALS AND METHODS}

\section{Chemicals and drugs}

- Amadol (tramadol HCL) was used in this study .It was purchased from El-Gomhuria Company for Chemicals and Medical Trading, Assiut, Egypt. Its chemical name is $(+)$ cis-2- [(dimethylamino) methyl]-1-(3-m ethoxyph-enyl) cyclohexanol hydrochloride. The Other reagents that were used for the histological and immunohistochemical preparations were purchased from commercial sources and were of analytical grade. 
- The primary antibodies; inducible nitric oxide synthase (iNOS) and Bcl2 were purchased from (Thermo scientific company, USA). The kits were obtained from Dako Life Trade, (Egypt).

\section{Experimental Animals}

A total number of thirty adult virgin female Wistar albino rats (their ages ranged between 3 and 4 months), weighing 160-200 g were used in this study. The animals were confined in clean properly ventilated cages containing bedding of fine wood which was changed twice weekly in the animal house of Assiut University. The animals were kept under standard conventional laboratory conditions at a temperature of $(25 \pm 5){ }^{\circ} \mathrm{C}$, with a humidity of $50 \pm 5 \%$ and a 12-h/12-h light/dark cycle. The rats were supplied with food and water ad libitium.

\section{Experimental protocol}

The experiment protocol used in this study was approved by the Institutional Animal Research Committee of the Faculty of Medicine, Assiut University, Egypt. At the start of the experiment, vaginal smears were taken daily from the animals inserting a glass rod smoothly into the vagina. The smears were prepared and stained with hematoxylin and eosin (H\&E) for the detection of three cell types; cornified cells, leukocytes and epithelial cells. The estrous cycle phase was determined by observing the proportions of these cells ${ }^{[11]}$. Rats at estrous cycle phase were randomly divided into two groups:

\section{Control group}

Had ten rats. The animals of this group were given saline $9 \%$ subcutaneously three times weekly for 8 weeks.

Experimental group that was further divided into two subgroups, each contained ten rats:

\section{Treated group}

The animals of this group was treated with Amadole (tramadol hydrochloride) subcutaneously in a dose of 40 $\mathrm{mg} / \mathrm{kg}$ body weight three consecutive times weekly for 8 weeks $^{[12]}$.

\section{Withdrawal group}

The rats of this group were subcutaneously injected with Amadole (tramadol hydrochloride) $40 \mathrm{mg} / \mathrm{kg}$ body weight $^{[12]}$ three consecutive times per week for 8 weeks ,then were kept for another 8 weeks without treatment for recovery.

At the end of the experiment the rats were sacrificed under ether anesthesia. A medial longitudinal incision was done in the lower part of the abdomen and the ovaries could be identified by their connection to the lateral free end of the fallopian tubes. Then bilateral oophorectomy was done. The ovaries were dissected and processed for further techniques; histological study and immunohistochemically reaction.

\section{Histological study \\ Light microscopic study}

The ovaries of the three groups were incised and fixed in $10 \%$ phosphate buffered formalin ( $\mathrm{pH} 7.4$ ) for 48 hours. The specimens were dehydrated in ascending grades of ethyl alcohol, cleared in xylene and embedded in paraffin. Serial $5 \mu \mathrm{m}$ thick sections were cut and stained with Hematoxylin and eosin (H\&E) and Masson's trichrome stains $^{[13]}$.

\section{Transmission electron microscopic study}

Specimens of the ovary about $(1 \mathrm{X} 1 \mathrm{~mm})$ were taken and fixed in phosphate buffered glutaraldehyde for about 24 hours and post- fixed in $1 \%$ osmium tetroxide for one hour. Then embedded in araldite. Semithin sections $(1 \mu \mathrm{m})$ were prepared and stained by toluidine blue. Ultrathin sections of 50-60 $\mathrm{nm}$ from the selected areas were cut by an ultra-microtome and contrasted with uranyl acetate and lead citrate ${ }^{[14]}$. The stained ultrathin sections were examined and photographed with transmission electron microscope (Joel- JEM- 100 CXII; Joel, Tokyo, Japan) in Assiut University, Electron Microscopic Unit.

\section{Immunohistochemical study}

Tissue sections were dewaxed, rehydrated and treated with $10 \%$ hydrogen peroxide to reduce endogenous peroxidase. Then the sections were boiled in citrate buffer pH 6.0 and left to cool. The ovarian sections were incubated with the primary antibodies: $\mathrm{Bcl} 2$, a mouse monoclonal antibody (clone c-2) (Neo Markers Laboratories, Fremont, California, USA). The sections were incubated with secondary antibody; a biotinylated goat anti-rabbit immunoglobulin, followed by a streptavidin-biotin complex. The reaction site was detected through adding diaminobenzidine $\mathrm{HCl}$, which in turn converted into a brown precipitate by peroxidase. The slides stained with Mayer's hematoxylin ${ }^{[15]}$.

Immunohistochemically stained paraffin sections were prepared for the detection of inducible nitric oxide synthase (iNOS). The reaction was carried by using streptavidin system with antibody against the iNOS marker for oxidative stress. Sections were deparafinized, hydrated, washed in $0.1 \mathrm{~mol} / \mathrm{l} \mathrm{PBS}$ and treated with trypsin $0.01 \%$ for $10 \mathrm{~min}$ at $37^{\circ} \mathrm{C}$. Then washed with PBS for about 5 $\min$. The sections were incubated with a primary antibody (Rabbit Polyclonal Antibody), which was diluted 1:100 overnight at $4^{\circ} \mathrm{C}$. The reaction could be detected by using $0.05 \%$ diaminobenzidine. The slides were stained with Mayer's hematoxylin. The positive results for the immune reaction were detected as brown cytoplasmic coloration ${ }^{[16]}$.

\section{Morphometrically study}

The area $\%$ of the collagen fibers in the cortical stroma and that of the iNOS immunohistochemically reactions in the cytoplasm of the granulosa cells as well as in the stromal cells were measured in the sections stained 
with Masson's trichome and sections stained with iNOS immunohistochemically reactions respectively. The stained sections were examined by using CX41 optical microscope (Olympus, Center Valley, PA, USA) that was equipped by Olympus U-CMAD3 digital camera interfaced to computer. The area \% was determined by means of computer-assisted Image J software (NIH, Bethesda, MD, USA). The obtained data was expressed as mean \pm standard deviation (SD). Evaluation of the data was done using Social Sciences (SPSS, 16.0). The statistical significance of different groups was analyzed by ANOVA test. $p$-Value $<0.05$ was considered to be significant

\section{RESULTS}

\section{A. Histological results}

\section{Light microscopic results}

\section{Hematoxylin and Eosin stain $(H \& E)$}

In the control group, Hematoxylin and Eosin (H\&E) stained paraffin sections of the ovary showed the cortex of the ovary that contained various forms of ovarian follicles, corpus luteum and blood vessels; the primary ovarian follicles with oocytes and single layer of cuboidal follicular cells and the secondary follicles with large oocytes ,multilaminar granulosa cells and theca folliculi (Figure 1A). Notice the presence of mature Graafian follicles within the ovarian stroma. They were consisting of oocyte with a well-defined zona pellucida, many layers of granulosa cells and theca cells. The Theca interna cells were polygonal with open face nuclei and vacuolated cytoplasm. In contrast the cells of the theca externa were merging with the ovarian stroma and they were spindle in shape. The granulosa cells were polyhedral cells that surrounded the oocyte and lined the follicular cavity. The corpus luteum was identifiable with granulosa lutein cells. They were plump and polygonal cells with moderate amounts of eosinophilic cytoplasm and rounded pale nuclei. The ovarian stroma was recognized by the presence of fibroblast-like cells, spindle-shaped cells, delicate collagen fibers and ground substance (Figure 1B).

Sections stained with $H \& E$ of the tramadol treated group revealed the cortex of the ovary that contained various forms of degenerated ovarian follicles with loss of their normal architecture, corpus luteum and blood vessels within clusters of the interstitial stromal cells; some atretic follicles appeared with disrupted granulosa cells. The secondary follicles showed primary oocyte surrounded by granulosa cells and flat peripheral theca folliculi cells. The surrounding granulosa cells appeared swollen, disrupted, irregular in shape with degenerated vacuolated cytoplasm. Numerous pyknotic nuclei were observed. Some primary follicles had degenerated oocytes and surrounded with cuboidal granulosa cells; shrunken in some follicles and swollen with vacuolated cytoplasm in others. These follicles had hemorrhagic material within their cavities. The histological sections did not show any mature follicle. The blood vessels were dilated and congested. Their walls were apparently thick and had hypertrophied smooth muscle. Some vacuoles were detected within the stroma.In addition an increase in the fibroblast activity was observed. The corpus luteum showed some cells with densely stained nuclei .Also cells with cytoplasmic vacuolation were seen (Figures 1C,1D).

The H\&E stained sections of the withdrawal group did not present considerable improvement. The ovarian cortex had atretic follicles, degenerated primary follicles and corpus luteum. Secondary follicles showed atretic oocytes surrounded with degenerated granulosa cells and many vacuoles. Dilated and congested blood vessels were still observed. Some vacuoles were present within the stroma. The cells of the corpus luteum had pyknotic nuclei and vacuolated cytoplasm (Figure 1E).

\section{Masson's trichrome stain}

Examination of the Masson's trichrome-stained sections of the ovaries of control group showed normal distribution of the collagen fibers in the cortical stroma (Figure 2A). Masson's trichrome-stained sections of the ovaries of treated group had marked increase in the deposition of the collagen fibers in the ovarian cortical stroma (Figure 2B). The ovarian cortex of the withdrawal group showed increase in the deposition of the collagen fibers (Figure 2C).

\section{Toluidine blue stain}

Semi-thin section of the ovary of the control rats showed the mature Graafian follicles. These follicles were identified by the presence of oocytes at a peripheral position, surrounding with well-defined zona pellucida and corona radiata. The oocytes and the corona radiata were mound on a group of granulosa cells (cumulus oophorus).Large amount of liquor folliculi distended the antrum. Numerous layers of granulosa cells and theca cells surrounded the antral cavity. The granulosa cells had distinct boundaries of the cytoplasm and round euchromatic nuclei with one or two nucleoli. The theca cells differentiated into polyhedral theca interna and fusiform theca externa. No distinct boundary could be noticed between the two layers (Figures 3A,3B). Semi-thin section of the corpus luteum revealed the presence of granulosa lutein cells filling most of the field. They were large polygonal cells with large rounded pale nuclei and prominent nucleoli (Figure 4A). Semi-thin section of the tramadol treated rats showed atretic ovarian follicles. They had collapsed oocytes with undulated wall, ill-defined zona pellucida and interrupted corona radiata. The surrounding granulosa cells were represented with severe degenerative changes; disrupted, loosely attached with numerous pyknotic nuclei with condensed chromatin, indicating apoptosis and some of them were found to be shed within the follicular lumen. Marked vacuolation could be detected within the granulosa cells (Figures 3C,3D). The granulosa lutein cells of the corpus luteum were swollen and disrupted with irregular pyknotic nuclei and vacuolated cytoplasm. Some cells had rarified nuclei (Figure 4B). Semi-thin section of the 
withdrawal group showed distorted ovarian follicles with degenerated oocyte surrounded by severely degenerated widely separated granulosa cells with darkly stained nuclei and marked vacuolation. The cells of the corona radiate were irregular in shape, widely separated and had rarified nuclei (Figures 3E,3F). The corpus luteum appeared with many degenerated lutein cells. Rarified nuclei and vacuolated cytoplasm could be detected (Figure 4C).

\section{Ultrastructural results}

Ultra-thin sections of the ovary of the control group showed the fine structure contact between the zona pellucida and the oocyte of the mature Graafian follicle. The zona pellucida appeared as jelly homogeneous matrix with medium electron density filled completely the space between the oocyte and the adjacent granulosa cells of the corona radiata. Pseudopodia-like processes were observed radiating from the cells of the corona radiata towards the surface of the oocytes. This surface was irregular and rough because of the presence of numerous short and thin microvilli projecting outwards into the adjacent zona pellucida. The cytoplasm of the oocytes was divided into two regions; one region was rich in mitochondria and small granular bodies and the other region was relatively free of the granules .In addition, variable sized lamellae known as cytoplasmic rays and multi- vesicular bodies were also recognized in the cytoplasm. The cells of the corona radiata had euchromatic nuclei with prominent nucleoli. Notice the presence of oval mitochondria and numerous free ribosomes in the cytoplasm (Figures 5A,5B).

The granulosa cells of the mature follicles were morphologically identified with the presence of large euchromatic nuclei with distinct nuclear membrane and one or two prominent nucleoli. Their cytoplasm had well organized cell organelles like regularly arranged Golgi saccules located near the nuclei, mitochondria and numerous free ribosomes (Figure 6A).

In the sections of the treated group, obvious degeneration of the zona pellucida. Cellular debris and apoptotic cell bodies were detected within the zona pellucida. The processes radiating from the cells of the corona radiata towards the surface of the oocytes were illdefined and lost in many areas. The granulosa cells of the corona radiata showed fragmentation of their nuclear and cytoplasmic contents and their leakage (Figure 5C).

The ultrastructural adverse effects of tramadol on the granulosa cells of the atretic ovarian follicles were the most encountered. The cells were widely separated and numerous vacuolated areas were seen in between the cells. They had nuclei with peripheral chromatin margination. Some cells were noticed with thick irregular nuclei . Some nuclei were shrunken and hyperchromatic. The cytoplasm was rarified with the presence of marked vacuolation. The cytoplasmic organelles were scanty and haphazard in distribution and became un-identifiable. Apparent decrease in the amount of free ribosomes. Some lipid droplets were noticed. Apoptotic cell bodies and dilated congested blood capillaries could be seen (Figure 6B).

Examination of the withdrawal group revealed degenerative changes that were more or less similar to the treated group. The structure contact between the zona pellucida and the oocyte had some degenerative changes. The zona pellucida had a jelly homogeneous appearance with medium electron density. Some cellular debris and vacuolated area were detected within it. The cytoplasm of the oocyte showed cytoplasmic rays and scanty cellular organelles (Figure 5D). The granulosa cells of the distorted ovarian follicles had electron dense nuclei with ill-defined nucleoli. Marked irregularity of the nuclear envelope. The rarified cytoplasm was poor with cell organelles. Apparent decrease in the amount of free ribosomes, dilated perinuclear cisternae, lysosomes and marked vacuolation were noticed (Figure 6C).

\section{Immunohistochemical results}

Examination of the ovarian sections stained with anti$\mathrm{Bcl} 2$ antibodies revealed strong positive immunoreactivity for $\mathrm{Bcl} 2$ in the cytoplasm of most of the granulosa cells of the control group (Figure 7A). As regard the tramadol treated group, marked reduction in the immunostaining for $\mathrm{Bcl} 2$ was present. Moderate immunostaining for $\mathrm{Bcl} 2$ could be detected in few granulosa cells (Figure 7B). The withdrawal group did not show remarkable difference in comparison with the treated group (Figure 7C).

A weak immune reaction to iNOS was detected in the cytoplasm of the granulosa cells as well as in the stromal cells of the control group (Figure 8A). While the tramadol treated group was represented with strong positive immune reaction in the cytoplasm of most of the granulosa and stromal cells (Figure 8B). The withdrawal group showed intense immune reaction to iNOS in the cytoplasm of most of the granulosa and moderate immune reaction in the cytoplasm of the stromal cells (Figure 8C).

\section{B. Morphometric results}

The statistical analysis of the mean area \% of the collagen fibers was increased significantly in both the tramadol and the withdrawal groups in comparison to the control group (Table 1, Histogram 1). As regard the mean area $\%$ of of iNOS, there was a significant increase in both the treated and the withdrawal group as compared to the control group (Table 2, Histogram 2). 


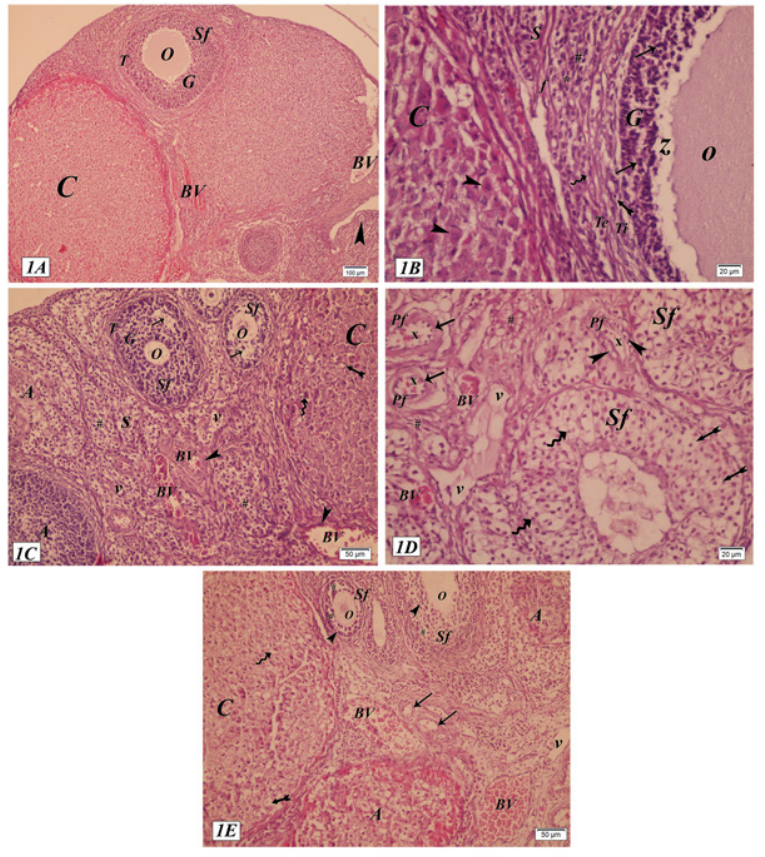

Fig. 1: Paraffin sections of a sagittal section in the ovary stained by H\&E. (1A) Control group shows the cortex of the ovary that has ovarian follicles , corpus luteum (C) and blood vessels (BV); the primary ovarian follicle with oocyte and single layer of cuboidal cells(arrow head ) and the secondary follicle (Sf) with large oocyte $(\mathrm{O})$, multilaminar granulosa cells $(\mathrm{G})$ and theca folliculi(T) (x100).(1B) Control group shows the mature Graafian follicle .Notice the presence of an oocyte (o) with a well-defined zona pellucida (z), many layers of granulosa cells $(\mathrm{G})$ and theca cells. The Theca interna (Ti) cells are polygonal with open face nuclei and vacuolated cytoplasm (tailed arrow). The cells of the theca externa (Te) are merging with the ovarian stroma and they are spindle in shape (wavy arrow).The granulosa cells are polyhedral cells that surround the oocyte and line the follicular cavity (arrows). The corpus luteum(C) is formed of granulosa lutein cells. They are plump and polygonal cells with eosinophilic cytoplasm and rounded pale nuclei (head arrows). The ovarian stroma(S) has fibroblast-like cells (\#), spindle-shaped cells (asterisk), delicate collagen fibers (f) and ground substance. (X 400 ).(1C) Treated group.The cortex of the ovary contains various forms of degenerated ovarian follicles, corpus luteum ( C) and blood vessels(BV) within the stromal cells(S); some atretic follicles(A) appear with disrupted granulosa cells. The secondary follicles (Sf) show primary oocyte (O) surrounded by disrupted swollen granulosa cells $(\mathrm{G})$ with vacuolated areas (arrows) and flat peripheral theca folliculi cells (T). The blood vessels (BV) are dilated and congested. Their walls have hypertrophied smooth muscle (arrow heads). Some vacuoles (v) and an increase in the fibroblast activity (\#) are within the stroma. The corpus luteum has some cells with densely stained nuclei (wavy arrow) .Also cells with cytoplasmic vacuolation (tailed arrow) are seen. (X200). (1D) Treated group. The surrounding granulosa cells of the secondary follicle (Sf) are swollen, disrupted, irregular in shape and have vacuolated cytoplasm (tailed arrows). Notice the presence of numerous pyknotic nuclei (wavy arrows). Some primary follicles (Pf) have degenerated oocytes and surrounded with cuboidal granulosa cells; shrunken (arrows) in some follicles and swollen with vacuolated cytoplasm in others (arrow heads). These follicles had hemorrhagic material within their cavities (x). In addition the stroma has vacuoles (v) and increase in the fibroblast activity (\#). Notice the dilated congested blood vessels (BV). (X400). (1E) Wthdrawal group. The ovarian cortex has atretic follicle (A), degenerated primary follicles (arrows) and corpus luteum (C). Secondary follicles (Sf) show atretic oocytes (O) surrounded with degenerated granulosa cells (arrow heads) and many vacuoles (\#). Dilated and congested blood vessels are observed (BV). Some vacuoles are noticed (v) within the stroma. The cells of the corpus luteum have pyknotic nuclei (tailed arrow) and vacuolated cytoplasm (wavy arrow). (X200).

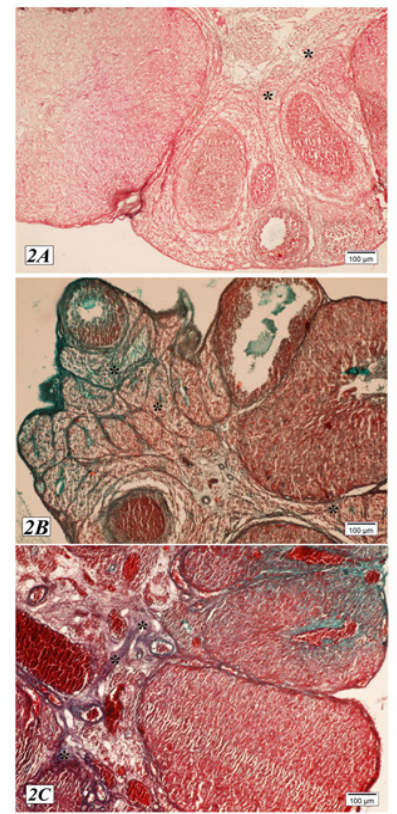

Fig. 2: Paraffin sections of a sagittal section in the ovary stained by Masson's trichrome. (2A) Control group shows normal distribution of the collagen fibers in the cortical stroma (asterisk). (2B) Treated group shows marked increase in the deposition of the collagen fibers in the ovarian cortical stroma (asterisk). (2C) Withdrawal group shows that the ovarian cortex appears with increase in the deposition of the collagen fibers (asterisk). (X100). 

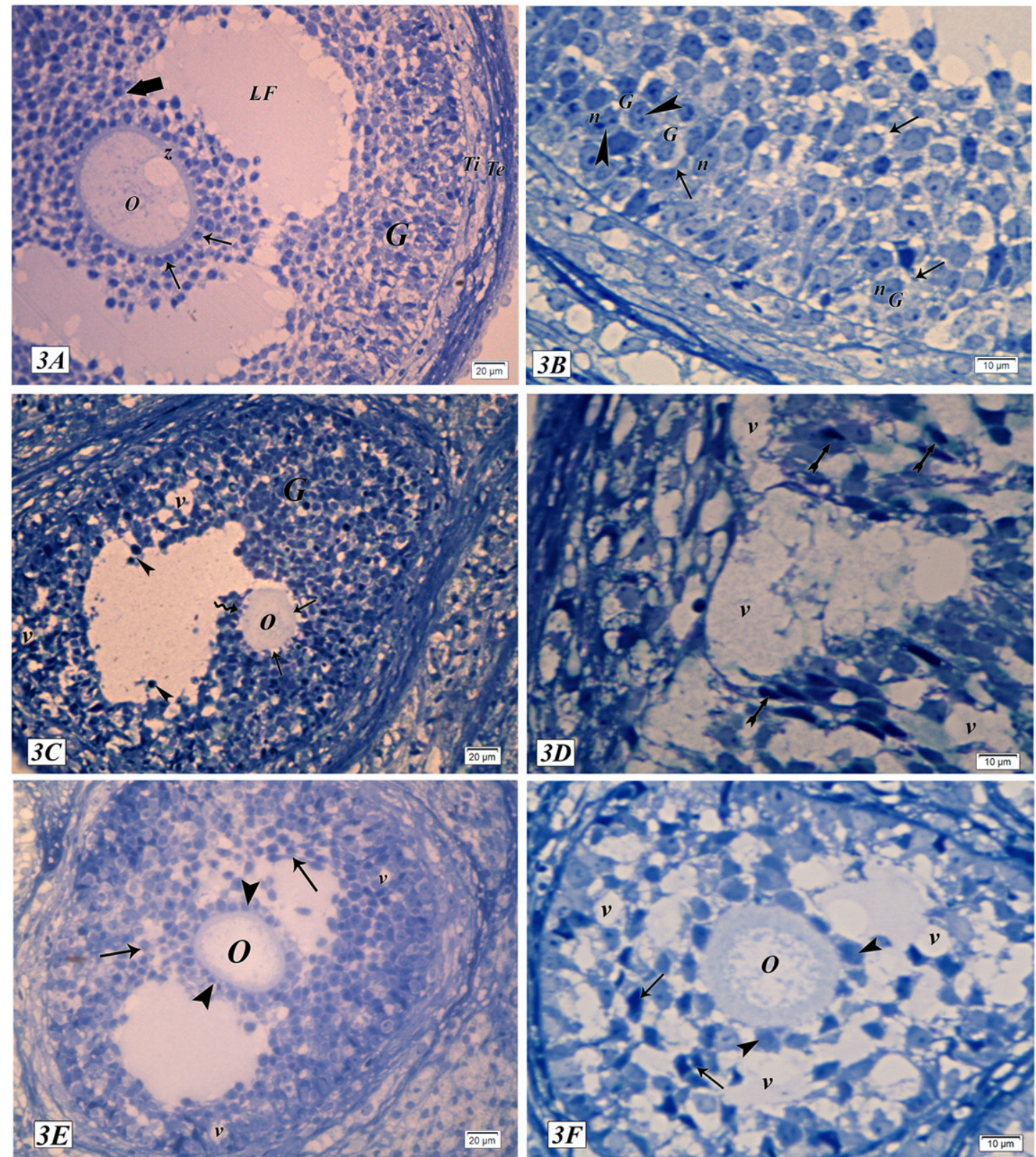

Fig. 3: Semithin sections in the ovary stained by toluidine blue. (3A) Control group shows the mature Graafian follicle. This follicle has oocyte (O) at a peripheral position, well-defined zona pellucida ( $\mathrm{z}$ ) and corona radiata (arrows). The oocytes and the corona radiata are mound on cumulus oophorus (thick arrow). Liquor folliculi (LF) distends the antrum. Numerous layers of granulosa cells (G) and theca cells surround the antral cavity. The theca cells differentiated into theca interna (Ti) and theca externa (Te). No distinct boundary can be noticed between the two layers. (X400). (3B) Control group showing the granulosa cells (G). They have distinct boundaries of the cytoplasm (arrows) and round euchromatic nuclei (n) with one or two nucleoli (arrow heads). (X1000). (3C). Treated group shows atretic ovarian follicle. It has collapsed oocyte (O) with undulated wall, ill-defined zona pellucida( arrows) and interrupted corona radiata (wavy arrow). The surrounding granulosa cells $(\mathrm{G})$ are represented with degenerative changes ; disrupted ,loosely attached and some of them are found to be shed within the follicular lumen (arrow heads). Marked vacuolation (v) can be detected within the granulosa cells. (x400). (3D) Treated group showing the granulosa cells. They have numerous pyknotic nuclei with condensed chromatin (tailed arrows) and vacuolations (v). (x1000). (3E \&3F) Withdrawal group shows distorted ovarian follicle with degenerated oocyte $(\mathrm{O})$ surrounded by severely degenerated widely separated granulosa cells with darkly stained nuclei(arrows) and marked vacuolation (v). The cells of the corona radiate are irregular in shape, widely separated and have rarified nuclei (arrow heads). (x400 \&x1000 respectively). 


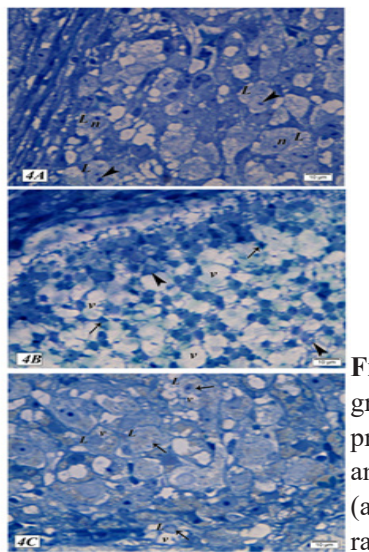

Fig. 4: Semithin sections in the ovary stained by toluidine blue. (4A) Control group shows the corpus luteum. The granulosa lutein cells (L) filling most of the field. They are large polygonal cells with large rounded pale nuclei (n) and prominent nucleoli (arrow heads). (4B) The treated group .The granulosa lutein cells of the corpus luteum are swollen and disrupted with irregular pyknotic nuclei (arrows) and vacuolated cytoplasm (v) .Some cells had rarified nuclei (arrow heads ) . (4C) Withdrawal group .The corpus luteum appears with many degenerated lutein cells (L). They show rarified nuclei (arrows) and vacuolated cytoplasm (v). (x1000).
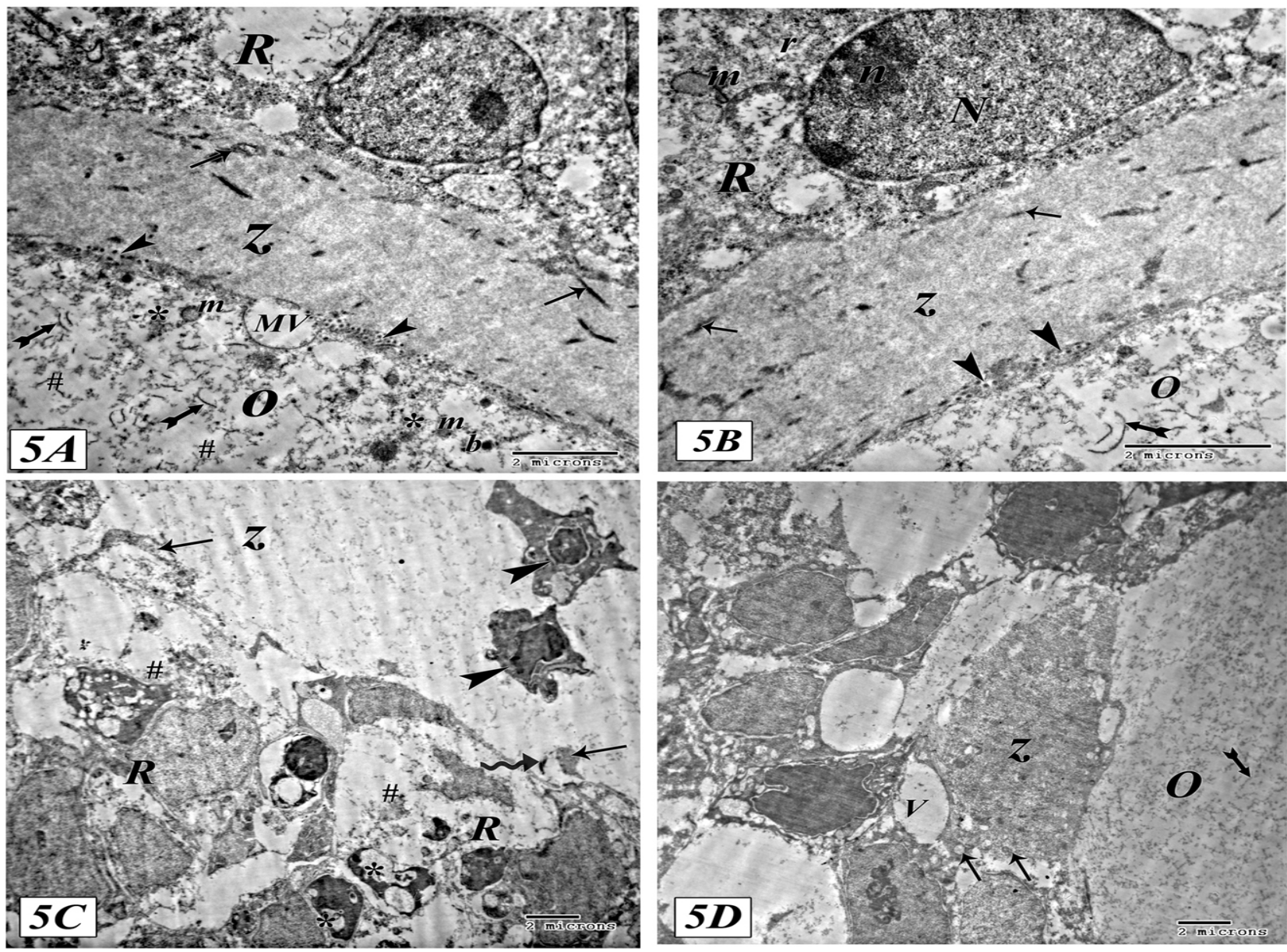

Fig. 5: TEM of the ovary. (5A) The control group shows the fine structure contact between the zona pellucida and the oocyte of the mature Graafian follicle The zona pellucida $(\mathrm{z})$ is jelly homogeneous matrix with medium electron density fills completely the space between the oocyte (O) and the adjacent granulosa cells of the corona radiata (R). Pseudopodia-like processes (arrows) are observed radiating from the corona radiata towards the surface of the oocytes. This surface is irregular and rough because of the presence of numerous short and thin microvilli (arrow heads) projecting outwards into the adjacent zona pellucida. The cytoplasm of the oocytes is divided into two regions ; one region(asterisk) is rich in mitochondria(m) and small granular bodies(b) and the other region is relatively free of the granules(\#) .In addition, variable sized lamellae known as cytoplasmic rays (tailed arrows) and multi- vesicular bodies (MV) are also recognized in the cytoplasm. (X7200). (5B) Control group showing pseudopodia-like processes(arrows) radiate from the cells of the corona radiata (R) towards the surface of the oocytes $(\mathrm{O})$. Notice numerous microvilli (arrow heads) project outwards into the adjacent zona pellucida (z). In addition, tailed arrow points to cytoplasmic rays. The cells of the corona radiata have euchromatic nuclei $(\mathrm{N})$ with prominent nucleoli $(\mathrm{n})$. Notice the presence of oval mitochondria $(\mathrm{m})$ and numerous free ribosomes (r) in the cytoplasm (X10000). (5C). Treated group shows parts of the zona pellucida (z) and the adjacent cells of the corona radiata (R). Cellular debris (arrows) and apoptotic cell bodies (arrow heads) are detected within the obviously degenerated zona pellucida. The granulosa cells of the corona radiata show fragmentation of their nuclear (asterisk) and cytoplasmic (\#) contents and their leakage. The processes radiating from the cells of the corona radiata towards the surface of the oocytes are ill-defined and lost in many areas (wavy arrow). (X2900). (5D) Withdrawal group shows the structure contact between the zona pellucida and the oocyte. The zona pellucida (z) has a jelly homogeneous appearance with medium electron density. Some cellular debris (arrows) and vacuolated areas (V) are detected within it. The cytoplasm of the oocyte shows cytoplasmic rays (tailed arrow) and scanty cellular organelles. (X3600) 


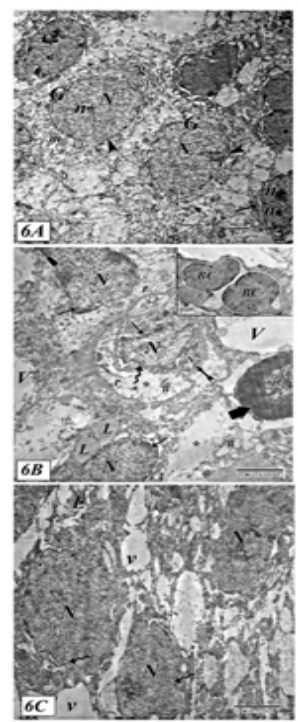

Fig. 6: TEM of the ovary. (6A) Control group shows the granulosa cells $(\mathrm{G})$ of the mature follicles. They are morphologically identified with the presence of large euchromatic nuclei $(\mathrm{N})$, prominent nucleoli $(\mathrm{n})$ with distinct nuclear membrane (arrow heads). Notice the presence of two prominent nucleoli (n) in some cells (arrow). Their cytoplasm has well organized cell organelles like regularly arranged Golgi saccules (g) located near the nuclei, mitochondria (m) and numerous free ribosomes (r). (X3600). (6B) Treated group shows the granulosa cells of the atretic ovarian follicles. Wide separation of the cells with numerous vacuolated areas $(\mathrm{V})$ in between. They have nuclei $(\mathrm{N})$ with peripheral chromatin margination (arrows). Some cells were noticed with thick irregular nuclei (wavy arrow). Some nuclei are shrunken and hyperchromatic (tailed arrow). The cytoplasm is rarified (\#) with the presence of marked vacuolation (asterisk). The cytoplasmic organelles are scanty and haphazard in distribution and become un-identifiable . Apparent decrease in the amount of free ribosomes (r) is noticed. Some lipid droplets (L) are noticed. Thick arrow points to apoptotic cell bodies (x 7200). Inset: shows the dilated congested blood capillaries (BC) .x10000. (6C) Withdrawal group. The granulosa cells of the distorted ovarian follicles have electron dense nuclei (N) with ill-defined nucleoli. Marked irregularity of the nuclear envelope (wavy arrows). The rarified cytoplasm is poor with cell organelles (\#) .Apparent decrease in the amount of free ribosomes(r), dilated perinuclear cisternae(asterisk), lysosomes(L) and marked vacuolation(V) can be noticed . (x7200)

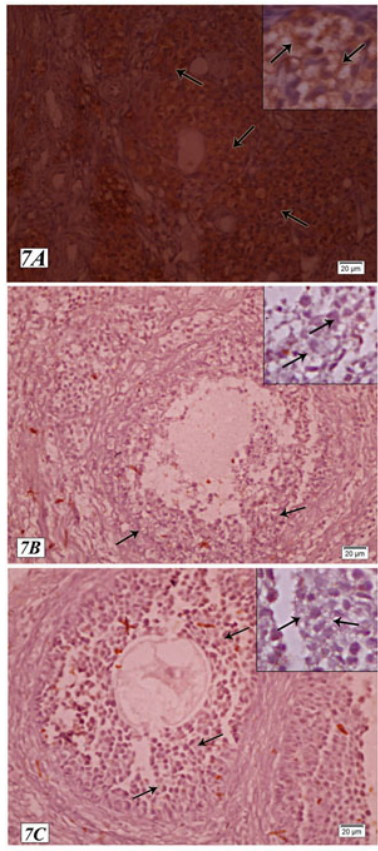

Fig. 7: Bcl immunohistochemically stained sections in the ovary. (7A) Control group; strong positive immunoreactivity for Bcl2 in the cytoplasm of most of the granulosa cells can be observed (arrows) $(\times 400)$.inset: A higher magnification shows the strong positive immunoreactivity for Bcl2 in some of granulosa cells (arrows). ( $\times 1000)$. (7B) Treated group shows moderate immunostaining for Bcl2 in few granulosa cells (arrows) $(\times 400)$. Inset: A higher magnification shows moderate immunostaining for $\mathrm{Bcl} 2$ in the granulosa cells (arrows) $(\times 1000)$. (7C) Withdrawal group does not show remarkable difference in comparison with the treated group (arrows) $(\times 400)$. Inset: A higher magnification shows moderate immunostaining for Bcl2 in the granulosa cells $($ arrows $)(\times 1000)$. 


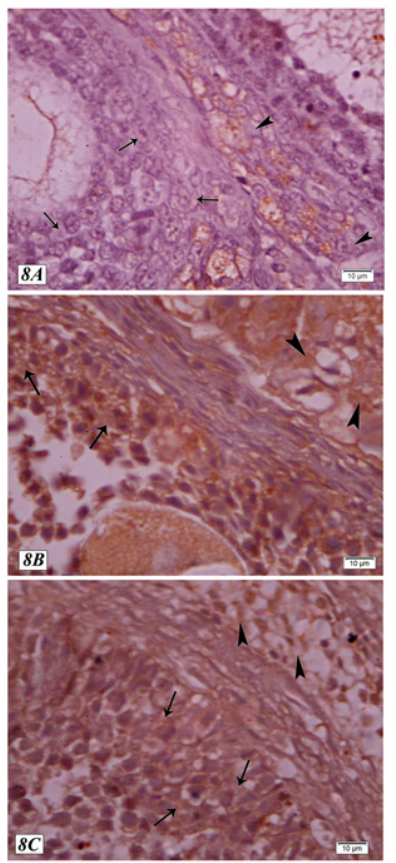

Fig. 8: iNOS immunohistochemically stained sections in the ovary. (8A) Control group shows weak immune reaction to iNOS in the cytoplasm of the granulosa cells (arrows) as well as in the stromal cells (arrow heads). (8B) Treated group. Strong positive immune reaction in the cytoplasm of most of the granulosa (arrows) and stromal cells (arrow heads) are observed. (8C) Withdrawal group shows intense immune reaction to iNOS in the cytoplasm of most of the granulosa (arrows) and moderate immune reaction in the cytoplasm of the stromal cells(arrow heads). $(\times 1000)$.

Table 1: Mean area\% of collagen fibers of the different groups; group I(control), group II(treated) and group III(withdrawal) . Data are presented as mean \pm standard deviation $(\mathrm{SD})$.

\begin{tabular}{|c|c|c|c|c|c|c|}
\hline Area $\%$ of collagen & Group I & Group II & Group III & $P$-value ${ }^{1}$ & $P$-value ${ }^{2}$ & $P$-value ${ }^{3}$ \\
\hline Mean \pm SD & $82.78 \pm 7.07$ & $132.79 \pm 14.10$ & $122.22 \pm 10.59$ & \multirow{2}{*}{$0.005^{*}$} & \multirow{2}{*}{$0.006^{*}$} & \multirow{2}{*}{0.358} \\
\hline Range & $74.8-88.3$ & $117.0-144.2$ & $116.0-134.5$ & & & \\
\hline$P$-value 1 (group I vs. & & \multicolumn{2}{|c|}{$P$-value ${ }^{2}$ (group I vs. group III) } & \multirow{2}{*}{\multicolumn{3}{|c|}{$P$-value ${ }^{3}$ (group II vs. group III) }} \\
\hline$*$ : significant $(P<0.05)$ & & \multicolumn{2}{|c|}{ Ns: non-significant $(P>0.05)$. } & & & \\
\hline
\end{tabular}

Table 2: Mean area\% of iNOS of the different groups; group I (control), group II (treated) and group III (withdrawal). Data are presented as mean \pm standard deviation (SD).

\begin{tabular}{|c|c|c|c|c|c|c|}
\hline Area $\%$ of iNOS & Group I & Group II & Group III & $P$-value ${ }^{1}$ & $P$-value ${ }^{2}$ & $P$-value ${ }^{3}$ \\
\hline Mean \pm SD & $89.93 \pm 7.23$ & $152.51 \pm 6.35$ & $149.91 \pm 5.28$ & \multirow{2}{*}{$0.000^{*}$} & \multirow{2}{*}{$0.000^{*}$} & \multirow{2}{*}{0.552} \\
\hline Range & $85.8-100.7$ & $145.4-159.4$ & $144.2-156.7$ & & & \\
\hline
\end{tabular}

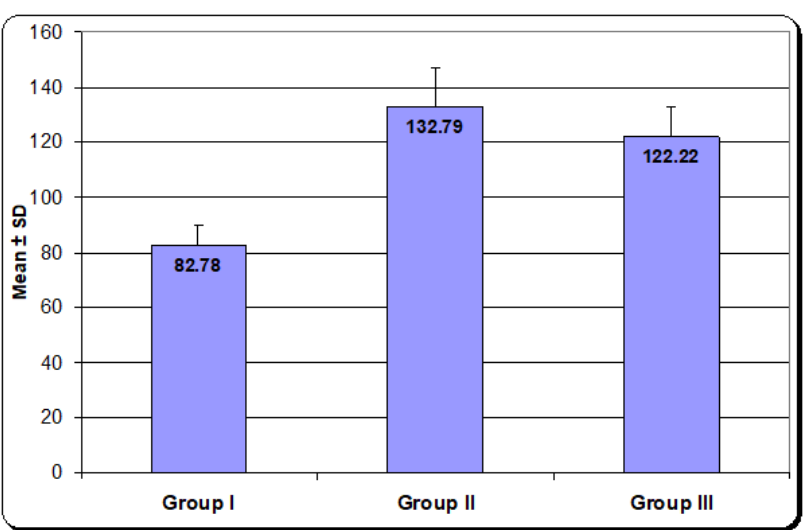

Histogram 1: The mean values of the area percentage of collagen fibers of the different groups; group I (control), group II (treated) and group III(withdrawal).

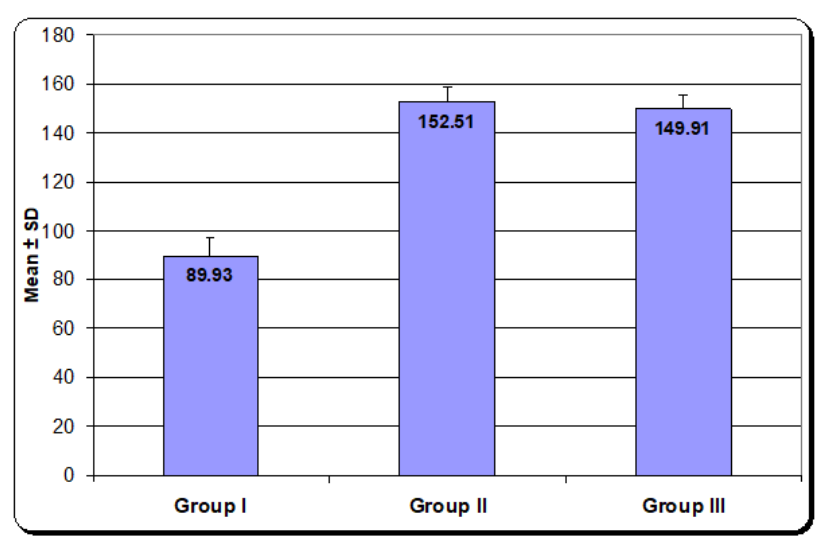

Histogram 2: The mean values of the area percentage of iNOS of the different groups; group I (control), group II(treated) and group III(withdrawal) 


\section{DISCUSSION}

Opioids are considered as the most promising substances for pharmacological pain relief ${ }^{[17]}$. Tramadol hydrochloride; a synthetic analogue of codeine, is one of the centrally acting analgesic drugs ${ }^{[18]}$. Nowadays tramadol has great interest as it is widely prescribed for moderate to severe pain ${ }^{[19]}$. The Egyptian society showed an increasingly alarming rate of tramadol addiction in the last years ${ }^{[20]}$. The several side effects of tramadol should be considered. One of these considered side effects is hypogonadism ${ }^{[21]}$. So the current study was run out to investigate the deleterious effects of tramadol administration and the possible recovery after its withdrawal on the ovary of adult female virgin albino rats.

The recommended daily dose of tramadol is recorded as $50-100 \mathrm{mg} / 4-6$ hours and to avoid the side effects of higher doses of tramadol, the daily dose should not exceed $400 \mathrm{mg} /$ day $^{[22]}$. Abdelaleem et al., 2017 ${ }^{[23]}$ stated that following an oral administration, the LD50 of tramadol in rat was $350 \mathrm{mg} / \mathrm{Kg}$ body weight. He added that the LD50 of $200 \mathrm{mg} / \mathrm{Kg}$ body weight was recorded in rat following subcutaneous dose. In this study tramadol was given subcutaneously in a dose of $40 \mathrm{mg} / \mathrm{kg}$ body weight (about $20 \%$ of the subcutaneous LD50 of tramadol in rats).

In this study, hematoxylin and eosin stained paraffin sections of the treated group revealed various forms of degenerated ovarian follicles with loss of their normal architecture; some atretic follicles appeared with disrupted granulosa cells. The secondary follicles showed primary oocyte surrounded by granulosa cells and flat peripheral theca folliculi cells. The surrounding granulosa cells appeared swollen, disrupted, irregular in shape with degenerated vacuolated cytoplasm. Numerous pyknotic nuclei were observed. The histological sections did not show any mature follicle. The blood vessels were dilated and congested. Their walls were apparently thick and had hypertrophied smooth muscle. Some vacuoles were detected within the stroma. The corpus luteum showed some cells with densely stained nuclei. Also cells with cytoplasmic vacuolation were seen. The results of the present work was in agreement with studies carried out by El-Ghawet, 2015 $5^{[12]}$ who found that oral administration of tramadol hydrochloride suspended in saline solution equal to $40 \mathrm{mg} / \mathrm{Kg}$ body weight for 30 days resulted in deterioration of the ovarian follicles; average of cystic and atretic follicles as well as of corpora like structure were present in the ovarian stroma. This noticed depletion was associated with disturbance of the ovarian function as measured by the duration of estrous cycle and the number of ovulated oocytes. It has been reported that tramadol is known to be a mixture with a double mechanism of action that resulted from both its opioid and non-opioid (inhibition of monoamine uptake) effects ${ }^{[24]}$.

Ahmed and Kurkar, 2014 ${ }^{[25]}$ demonstrated that female rats received tramadol $40 \mathrm{mg} / \mathrm{kg}$ body weight subcutaneously three times per week for 8 weeks showed reduction in the plasma levels of follicle-stimulating hormone and luteinizing hormone. Obvious reproductive failure was associated with administration of similar drugs such as opioid antagonist naloxone to the female rats ${ }^{[26]}$.

It has been recorded that either endogenous or exogenous opioids alternate the cellular activity of the hypothalamus and the pituitary gland ${ }^{[27]}$. In addition opioid affected the release of gonadotropin-releasing hormone at the level of the hypothalamus with subsequent decrease in the release of FSH and LH from the pituitary ${ }^{[28]}$. This reduction was explained by Bliesener., et al., 2005 ${ }^{[29]}$ who recorded that the tramadol effect on the gonadotropin-releasing hormone was by the increased levels of prolactin. These observed results suggested that tramadol treatment could affect the hypothalamo-hypophyseal-gonadal axis ${ }^{[30]}$.

Moreover, the Masson's trichrome-stained sections showed increase in the deposition of the collagen fibers in the ovarian cortical stroma of the tramadol treated rat. The histological results of the present work were supported with the statistical results; the mean area $\%$ of the collagen fibers was increased significantly in the tramadol treated group in comparison to the control group. Surazynski et al. $2008^{[31]}$ stated that the collagen fiber was presented as a ligand for integrin receptors; these receptors play a critical role in the signaling that control lipid metabolism, kinase activation and gene expression. So the changes that occurred in distribution and structure of the collagen fibers affected cell metabolism and function. Altindag et al., $2007^{[32]}$ suggested that the increase in the deposition of the collagen fibers resulted from the decrease in the collagen metabolism that could be due to oxidative stress.

The ultrastructural adverse effects of tramadol on the granulosa cells of the atretic ovarian follicles were the most encountered. They had nuclei with peripheral chromatin margination. Some cells were noticed with thick irregular nuclei. Some nuclei were shrunken and hyperchromatic. Dilated congested blood capillaries could be seen. These results were in accordance Quang-Cantagrel et al., 2000 ${ }^{[33]}$ who explained the tramadol toxicity at the cellular level was owing to the tramadol induced oxidative stress. He added that this oxidative stress resulted in the production of the reactive oxygen species which in turn combined with proteins, lipids and nucleic acid and resulted in the change of their structure and hence their function with damage of the affected cell . In harmony with these results ,Abdelaleem et al., 2017 ${ }^{[23]}$ found that the tramadol induced oxidative damage could be explained by the production of oxygen free radicals which in turn attack the cellular membrane and resulted in disintegration and destabilization of the membrane. In the present study, the cytoplasm of the granulosa cells was presented with marked vacuolation. In accordance to Mohamed et al., 2014 ${ }^{[34]}$ the cytoplasmic vacuolation resulted from swelling of the mitochondria and dilatation of the endoplasmic reticulum.

In this study the observed dilated congested blood capillaries could be explained by the vasodilatory effect of 
the produced nitric oxide ${ }^{[35]}$. Abdel- Zaher et al., 2011 ${ }^{[36]}$ found that tramadol administration for consecutive days increased nitric oxide levels in the brain which played a critical role in the development of the ovarian follicles, function of the corpus luteam and ovulation ${ }^{[37]}$.

Ultrastructure examination of the granulosa cells showed the cytoplasmic organelles were scanty and haphazard in distribution and became un-identifiable. These results were in harmony with Cao and Kaufman, 2014[38] who stated that intra- and extracellular stimuli which resulted in the accumulation of misfolded proteins in the lumen of the endoplasmic reticulum. These abnormal proteins enhanced adaptive cellular response called the unfolded protein response (UPR), in order to compensate this disturbance ${ }^{[39]}$. As a result of the endoplasmic reticulum stress deformed cycles of breakdown and bond formation enhanced reactive oxygen species (ROS) accumulation. Alongside, the stressed endoplasmic reticulum released calcium which triggered ROS production by the mitochondria ${ }^{[40]}$. In harmony with that Fulda et al., 2010 ${ }^{[4]}$ reported that many physiological and pathological effects were controlled by ROS which considered as critical signaling molecules. Increased levels of ROS caused cellular dysfunction by damaging the bio-molecules and might lead to apoptotic cell death ${ }^{[42]}$.

A study done by Osadolor and Omo-Erhabor,2016 $6^{[43]}$ stated that long-term treatment with opioid resulted in obvious suppression of hypothalamo-pituitary-adrenal and -gonadal axes with suppression of the secretion of ovarian estrogen; the female principal sex hormone. This was in agreement with Stephen and Joshua, 2009 ${ }^{[44]}$ who reported decrease levels of LH and FSH by opioid, indicating interference with the hypothalamic pituitary regulation. Chronic morphine administration resulted in oxidative stress-related genes in rat model ${ }^{[45]}$. They added that the oxidative stress might be differ according to the age. Previous vitro studies stated that exposure to opioid receptor agonists increased the possibility of cell death by apoptotic mechanisms ${ }^{[46]}$.

Immunohistochemically, the tramadol treated group had marked reduction in the immunostaining for Bcl2. This was in accordance with Mao et al., 2002 ${ }^{[47]}$ who stated that administration of tramadol caused downregulation of the antiapoptotic Bcl-2 protein, in addition to proapoptotic Bax protein an upregulation . Khodeary et al., 2010[2] added that the imbalance between both the antiapoptotic $\mathrm{Bcl}-2$ protein and the proapoptotic Bax protein resulted in apoptosis of the lymphocytes and activation of caspase- 3 .

The tramadol treated group was represented with strong positive immune reaction to iNOS in the cytoplasm of most of the granulosa and stromal cells. In harmony with that result, the treated group showed significant increase in the mean area $\%$ of iNOS as compared to the control group .Nitric oxide is considered as vital biological messenger. It is formed from 1-arginine by enzyme nitric oxide synthase (NOS). Nitric oxide is an important molecule responsible for controlling the hypothalamic-pituitary-gonadal axis ${ }^{[48]}$. It has been reported that low nitric oxide levels modulate the development of the ovarian follicles while its high concentration enhanced cell death through the formation of peroxynitrite ${ }^{[49]}$.

Hussein et al., 2017 $7^{[50]}$ stated that immuno-modulatory effect of tramadol was still not clear. He found that following tramadol administration there was increase in the serum level of IL-1B, TNF- $\alpha$ which indicated degeneration of the endogenous antioxidant defense system mechanisms. These observed results were similar to those recorded by Elwy and Tabl, 2014 ${ }^{[51]}$ who found that administration of tramadol for 30 days resulted in increased serum level of IL-1B. Many authors recorded an enhancing effect of tramadol on the immune activity, in vivo and in vitro; subcutaneous administration of tramadol enhanced the nature killer activity, and splenocyte proliferation in mice $^{[52]}$.

The results of the current work appeared with no remarkable differences between the tramadol treated group and the withdrawal group. Examination of the withdrawal group declared that the tramadol induced degenerative effects did not show considerable improvement in the rats which were kept for eight weeks without treatment for the recovery. The ovarian cortex of this group showed atretic follicles and degenerated primary follicles. In addition the secondary follicles appeared with atretic oocytes surrounded with degenerated granulosa cells and many vacuoles. Dilated and congested blood vessels were still observed. The electron microscopic examination of the granulosa cells of the distorted ovarian follicles showed electron dense nuclei with ill-defined nucleoli. The cytoplasm of these cells was rarified and poor with cell organelles.

In parallel with these histological results, statistical analysis revealed significant increase in the mean area $\%$ of the collagen fibers and that of iNOS in the withdrawal groups as compared to the control group. The histological results of the withdrawal group of the present work were in harmony with a study done by Ghoneim et al., 2014 ${ }^{[53]}$. They found that intraperitoneal treatment with $50 \mathrm{mg} /$ $\mathrm{kg}$ /day of tramadol for 4 weeks demonstrated obvious histological changes on both the testicular tissue and the cerebral cortex of adult male albino rat that were not completely improved in the withdrawal group that were kept for four weeks later without treatment and were comparable to the changes observed in the treated group. It was stated that tramadol has oxidative stress on various organs through the induction of inflammatory reaction ${ }^{[54]}$. This recorded inflammatory reaction was proved to be a principle factor for oxidative stress by the induction of changes in the composition of the cell membrane fatty acid following tramadol administration which in turn lead to a decrease of its fluidity and impaired formation of pseudopodia and internalization of both foreign particles and pathogens ${ }^{[55]}$. Tramadol as one of the synthetic opioids that has toxic effects at the cellular level through 
the increase of the lipid peroxidation ${ }^{[56,57]}$. The previous studies done by Zhang et al., 2004 ${ }^{[58]}$; Atici et al., 2005 $5^{[59]}$ reported that administration of morphine and tramadol reduced glutathione and catalase activities, glutathione peroxidase and superoxide dismutase .

\section{CONCLUSION AND RECOMMENDATION}

The results of the present work concluded the tramadol induced deleterious effects on the histological structure of the ovary .These impairment were not improved with the withdrawal of tramadol.

$\mathrm{SO}$, it is recommended to hold seminars for the students of high schools to obtain the information about the tramadol and its hazardous effects to reduce addiction among teenagers. It is recommended that patients with opioid therapy should be monitored for the occurrence of hypogonadism. In addition tramadol should not be sold without medical prescription. Finally further researches are needed on structural bases to highlight the tramadol induced ovarian insufficiency.

\section{CONFLICT OF INTERESTS}

There are no conflicts of interest.

\section{REFERENCES}

1. Ceccarelli I, De Pradova AM, Fiorenzani P, Massafra C, AloisiAM . Single opioid administration modifies gonadalsteroids in both the CNS and plasma of male rats. Neuroscience 2006;140:929-937.

2. Khodeary M K, Sharaf El-Din AA I, El Kholy S M S. A Histopathological and immunohistochemical study of adult rats' brain after long-term exposure to amadol (tramadol hydrochloride). Mansoura Journal of Forensic Medicine and Clinical Toxicology 2010; (1): 1-20.

3. Collett BJ. Chronic opioid therapy for non-cancer pain. Br J Anaesth 2001;87:133--143.

4. Liu H, Liu Z . The investigation of tramadol dependence with no history of substance abuse: a cross-sectional survey of spontaneously reported cases in Guangzhou City, China. BioMed Research International 2013; 283425:1-6.

5. Barlow S, Brooke G, Chatterjee K, Price G, Pelekanos R, Rossetti T, Doody M, Venter D, Pain S, Gilshenan K, Atkinson K. Comparison of human placenta- and bone marrow-derived multipotent mesenchymal stem cells. Stem Cells Dev 2008;17(6): 95-107

6. Tjäderborn M, Jönsson AK, Hägg S, Ahlner J. Fatal unintentional intoxication with tramadol during 1995-2005. Forensic Science International 2007; 173(2-3): 107-111.

7. Liu LW, Lu J, Wang XH, Fu SK, Li Q, Lin FQ. Neuronal apoptosis in morphine addiction and its molecular mechanism. International Journal of Clinical Experimental Medicine 2013; 6: 540-545.
8. Bhasin S, Cunningham GR, Hayes FJ, Matsumoto AM, Snyder PJ, Swerdloff RS, et al. Testosterone therapy in adult men with androgen deficiency syndromes: an Endocrine Society Clinical Practice guideline. The Journal of Clinical Endocrinology and Metabolism 2010; 95(6):2536-2559.

9. Elliott JA, Horton E, Fibuch EE. The endocrine effects of long-term oral opioid therapy: A case report and review of the literature. Journal of Opioid Management 2011; 7:145-154.

10. Shadnia S, Soltaninejad K, Heydari K, Sasanian G, Abdollahi M. Tramadol intoxication: a review of 114 cases. Human and Experimental Toxicology 2014; 27(3): 201-205.

11. Hubscher C, Brooks, D L , Johnson $\mathrm{J} R$.A quantitative method for assessing stages of the rat estrous cycle. Biotechnical and Histochemistry 2005; 80:79-87.

12. El-Ghawet HA .Effects of tramadol on the reproductive function of Wistar albino rats. European Journal of Experimental Biology 2015; 5(1):56-64.

13. Bancroft JD, Gamble M. Theory and practice of histological techniques. 6th ed. Edinburgh, London, New York, Tokyo: Churchill Livingstone; 2008. p. 121.

14. Hayat M A. Principles and techniques of electron microscopy: biological applications. $4^{\text {th }}$ ed. Edinburgh, UK: Cambridge University Press; 2000; 37-59.

15. Ramos-Vara JA . Principles and Methods of Immunohistochemistry. Methods in Molecular Biology . 2017; 1641 :115-128.

16. Kiernan J A. Histological and histochemical methods: theory and practice. 3rd ed. Oxford: A Hodder Arnold Publication; 2001.

17. Aloisi AM, Bonifazi M. Sex hormones, central nervous system and pain. Hormones and Behavior 2006; 50(1):1-7.

18. Rafati A, Yasini SM, Dashti-Rahmatabadi MH, Pakde S , Norani F .Tramadol Dependence Rate as Compared with Morphine in Rats. World Journal of Medical Sciences 2012; 1(1): 40-43.

19. Decker K, Cordonnier J, Jacobs W, Coucke $\mathrm{V}$, Schepens $\mathrm{P}$, et al. Fatal intoxication due to tramadol alone: case report and review of the literature. Forensic Science International 2008; 175(1): 79-82.

20. Fawzi MM. Some medicolegal aspects concerning tramadol abuse: the new Middle East youth plague 2010. An Egyptian overview. Egyptian Journal of Forensic Science 2011; 1:99-102. 
21. Reddy RG, Aung T, Karavitaki N, Wass JA. Opioid induced hypogonadism. BMJ 2010; 341:605-606.

22. Connor O A B, Turk D C, Dworkin R H. Abuse liability measures for use in analgesic clinical trials in patients with pain: IMMPACT recommendations. Pain 2013; 154:2324-2334.

23. Abdelaleem SA, Hassan OA.,Ahmed RF, Zenhom NM, Rifaai RA, El-Tahawy NF. Tramadol Induced Adrenal Insufficiency: Histological, Immunohistochemical, Ultrastructural, and Biochemical Genetic Experimental Study. Journal of toxicology 2017; 9815853:1-14.

24. Savadkoohi E, Vesa N. The analgesic interaction of tramadol and morphine in rats: An isobolographic study.Veterinary Research Forum 2019; 10(1): 31-36.

25. Ahmed M A, Kurkar A. Effects of opioid (tramadol) treatment on testicular functions in adult male rats: The role of nitric oxide and oxidative stress. Clinical and Experimental Pharmacolology and Physiology 2014; 41(4), 317.

26. Toit L D, Bennett NC, Gutjahr GH, Coen CW. Reproductive suppression in subordinate female highveld mole-rats (Cryptomys hottentotus pretoriae): No role for endogenous opioid peptides. Physiological and Behavior 2006; 87(5): 897 - 902.

27. Aloisi AM, Aurilio C, Bachioccco V, Biasi G, Fiorenzani P, Pace MC, Paci V, Pari G, Passavanti G, Ravaioli L, Sindaco G, Vellucci R, Ceccarelli I. Endocrine consequences of opioid therapy. Psychoneuroendocrinology 2009; 34(1): 162-168.

28. Michael J, Brennan MD. The effect of opioid therapy on endocrine function. The American Journal of Medicine 2013; 126:512-518.

29. Bliesener N, Albrecht S, Schwager A, Weckbecker $\mathrm{K}$, Lichtermann D, Klingmüller D. Plasma testosterone and sexual function in men receiving buprenorphine maintenance for opioid dependence. The Journal of Clinical Endocrinology and Metabolism 2005; 901: 203-206.

30. Katz N, Mazer NA .The impact of opioids on the endocrine system. The clinical Journal of Pain 2009; 25(2):170 -176.

31. Surazynski A, Miltyk W, Palka J, Phang JM. Prolidase-dependent regulation of collagen biosynthesis. Amino Acids 2008; 35(4):731- 738.

32. Altindag O, Erel O, Aksoy N, Selek S, Celik H, Karaoglanoglu M. Increased oxidative stress and its relation with collagen metabolism in knee osteoarthritis. Rheumatology International 2007; 27(4):339-344.
33. Quang-Cantagrel, N.D.; Wallace, M.S.; Magnuson, S.K. Opioid Substitution to Improve the Effectiveness of Chronic Noncancer Pain Control a Chart Review. Anesthesia . Analgesia. 2000; 90: 933-937.

34. Mohamed D, Saber A, Omar A, Soliman A. Effect of cadmium on the testes of adult albino rats and the ameliorating effect of zinc and vitamin E. British Journal of Science 2014 ; 11:72-95.

35. Sarhan NR, Taalab YM. Oxidative stress/PERK/ apoptotic pathways interaction contribute to tramadol neurotoxicity in rat cerebral and cerebellar cortex and thyme enhances the antioxidant defense system: histological, immunohistochemical and ultrastructural study International .Journal of Scientific Reports 2018; 4(6): 124 -141.

36. Abdel-Zaher AO, Abdel-Rahman MS, Elwasei FM. Protective effect of Nigella sativa oil against tramadol-induced tolerance and dependence in mice: Role of nitric oxide and oxidative stress. Neurology and Toxicology Journal 2011; 32: 725-33.

37. Pancarcı ŞM, Ari UC, Atakisi O, Güngör Ö, Çiğremiş $\mathrm{Y}$, Bollwein $\mathrm{H}$. Nitric oxide concentrations, estradiol-17 progesterone ratio in follicular fluid, and COC ßquality with respect to perifollicular blood flow in cows. Animal reproduction science 2012; 130(1):9-15.

38. Cao SS, Kaufman RJ. Endoplasmic reticulum stress and oxidative stress in cell fate decision and human disease. Antioxidants Redox Signaling 2014; 21(3):396-413.

39. Schröder M, Kaufman RJ. ER stress and the unfolded protein response. Mutation Research 2005; 569(1-2):29-63.

40. Malhotra JD, Kaufman RJ .Endoplasmic reticulum stress and oxidative stress: a vicious cycle or a double-edged sword? Antioxidants Redox Signaling 2007 9(12):2277-94.

41. Fulda S, Gorman AM, Hori O, Samali A. Cellular stress responses: cell survival and cell death. International Journal of Cell Biology $2010 ; 214074,1-23$.

42. Ott M, Gogvadze V, Orrenius S, Zhivotovsky B. Mitochondria, oxidative stress and cell death. Apoptosis 2007; 12(5):913-22.

43. Osadolor HB, Omo-Erhabor JA. Effects of Tramadol on Fertility Hormones (Follicle Stimulating Hormone, Luteinizing Hormone, Prolactin, Testosterone, Estrogen and $\beta$-HCG) in Laboratory Rabbits. British Journal of Medicine and Medical Research 2016; 14(8): 1-11. 
44. Stephen C, Joshua SC. Opioid-induced endocrinopathy. The Journal of American Osteopathic Association 2009; 109:20-25.

45. Bajic D, Berde CB, Commons KG. Periaqueductal gray neuroplasticity following chronic morphine varies with age: role of oxidative stress. Neuroscience 2012; 226: 165-177.

46. Sharifipour M, Izadpanah E, Nikkhoo B, Zare S, Abdolmaleki A, Hassanzadeh K, Moradi F, Has-sanzadeh K. new pharmacological role for donepezil: attenuation of morphineinduced tolerance and apoptosis in rat central nervous system. Journal of Biomedical Science $2014 ; 23: 21-26$

47. Mao J, Sung B, Ji RR, Lim G. Neuronal apoptosis associated with morphine tolerance: evidence for an opioid-induced neurotoxic mechanism. Journal of Neuroscience 2002; 17:7650-7661.

48. Dixit VD, Parvizi N. Nitric oxide and the control of reproduction. Animal Reproduction Science 2001; 65:1-16.

49. Tamanini C, Basini G, Grasselli F, Tirelli M. Nitric oxide and the ovary. Journal of Animal Science 2002; 81 (2): 1-7.

50. Hussein SA, Samir A, Abdel Aal SA, Ismail HK. Effect of tramadol drug on some biochemical and immunological parameters in albino male rats; evaluation of possible reversal following its withdrawal. Benha veterinary medical journal 2017; 33(2):418-429.

51. Elwy AM , Tabl G. Effects of Chronic Usage of Tramadol, Acetaminophen and Tramacet on Some Biochemical and Immunological Changes in Male Rats. Journal of Drug Research of Egypt 2014; 35(1):63-71.

52. Sacerdote P, Bianchi M, Manfredi B, Panerai AE. Efects of tramadol on immune responses and nociceptive thresholds in mice. Pain 1997; 72: 325-330.
53. Ghoneim F M, Khalafl HA, Elsamanoudy AZ, Helal AN. Effect of chronic usage of tramadol on motor cerebral cortex and testicular tissues of adult male albino rats and the effect of its withdrawal: histological, immunohistochemical and biochemical study. International Journal of Clinical and Experimental Pathology 2014; 7(11):7323-7341.

54. Rabei HM. The immunological and histopathological changes of Tramadol, Tramadol/ Acetaminophen and Acetaminophen in male Albino rats "Comparative study". The Egyptian Journal of Hospital Medicine 2011; 45: 477-503.

55. Alici HA, Ozmen I, Cezur M, Sahin F. Effect of the spinal drug tramadol on the fatty acid compositions of rabbit spinal cord and brain. Biological and Pharmaceutical Bulletin 2003; 26: 1403- 1406.

56. Popovic M, Janicijevic-Hudomal S, Kaurinovic B, Rasic J, Trivic S, Vojnović M. Antioxidant effects of some drugs on immobilization stress combined with cold restraint stress. Molecules 2009; 14: 4505- 4516 .

57. Salah S, Wagih M, Zaki A, Fathy W, Eid A Long-term effects of tramadol on the reproductive function of male albino rats: an experimental biochemical and histopathological study. Middle East Fertility Society Journal 2019; 24(3):1-6.

58. Zhang YT, Zheng Q.S, Pan J, Zheng RL. Oxidative Damage of Biomolecules in Mouse Liver Induced by Morphine and Protected by Antioxidants. Basic and Clinical Pharmacology and Toxicology 2004; 95: 53-58

59. Atici S, Cinel I, Cinel L, Doruk N ,Eskandari G. Oral U. Liver and Kidney Toxicity in Chronic Use of Opioids: An Experimental Long Term Treatment. Journal of Biosciences 2005; 30: 245-252. 


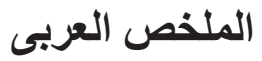

دراسة هستولوجية وهستوكيميائية لتأثيرات اعطاء عقار الترامادول على مبايض

الجرذان البيضاء البالغة والتعافى المحتمل بعد انسحابه

هائه زين العابدين محمد و هبة كمال محمد

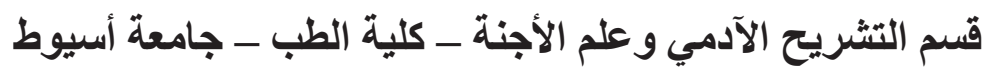

المقدمة: ترامادول هيدروكلور ايد هو احد المركبات الافيونية الاصطناعية ذات التأثير المركزى وقد ثبت انه فعال جدا

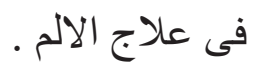

الهيف من البحث: هذا البحث يستهدف دراسة التأثير ات المؤذية الناتجة عن تعاطى الترامادول على مبايض الجرذان

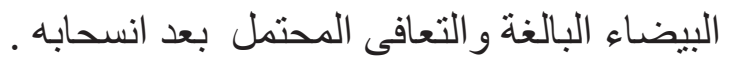

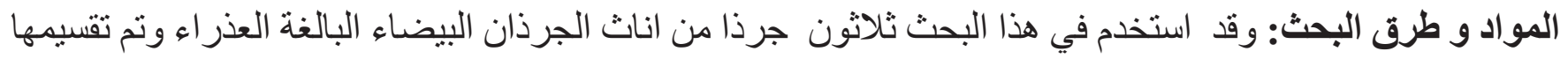

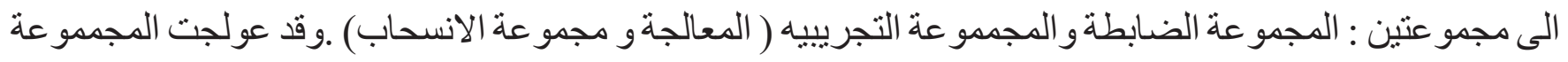

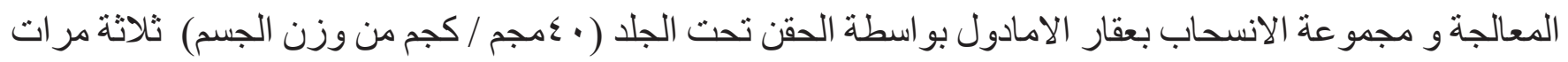

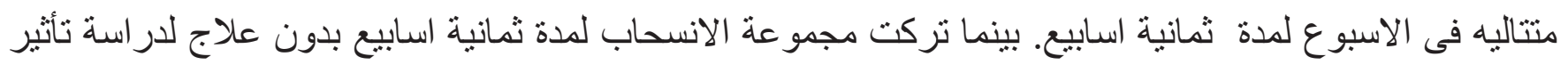

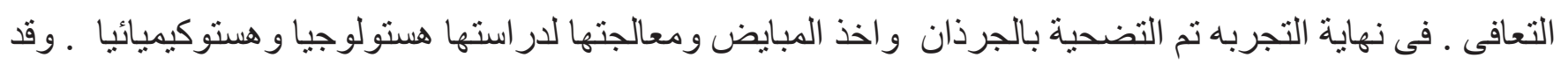
تم عمل در اسه احصائية بالاضافه.

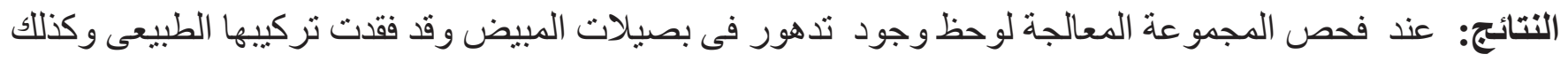

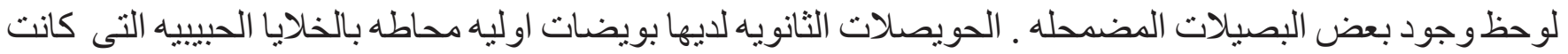

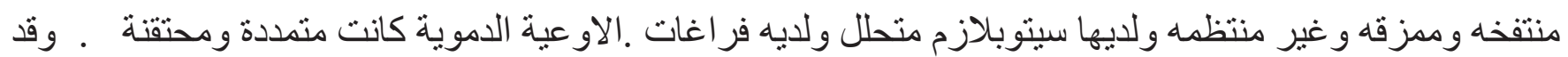

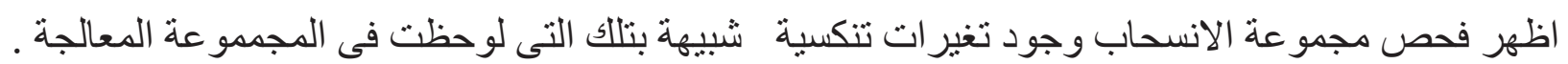

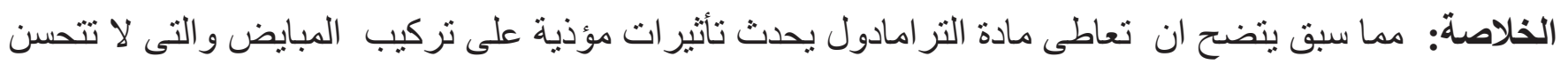

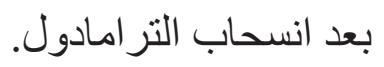

